\title{
Considering the Cost of Inclusionary Zoning and Resale Restrictions in the District of Columbia
}

\author{
By Laura K. Gibbons
}

This paper considers the economic impact of the District of Columbia's Inclusionary Zoning (IZ) affordable housing program, which provides low- and moderate-income families with the option of purchasing housing units below market price. The economic costs imposed by the IZ program include a loss of market surplus and the opportunity cost of capital for low- and moderate-income homebuyers. I evaluate resale restrictions in comparison to the shared equity provision of San José's IZ program, which allows homebuyers to sell their IZ units at market rates, retain the appreciation value of any improvements to the home, and refund the difference between the two to the San Jose city government, reducing the loss in market surplus and allowing homebuyers to retain an appreciable asset. I recommend that the DC IZ program relax its permanent resale restrictions and adopt the San José "recapture" model to reduce housing market losses to the benefit of both IZ homebuyers and the DC community as a whole.

\section{Introduction}

For low-income households, homeownership can provide many benefits related to the increased sense of well-being and life satisfaction, wealth accumulation, and housing security (McCarthy, Rohe, and Van Zandt 2001). The standard financial advice for households is that no more than one third of a monthly budget should be spent on housing costs. However, approximately 15.6 percent of US households, or 18.1 million households, spent more than half of their income on housing in 2012 (Sturtevant and Viveiros 2014). To provide low-income households with housing security and to promote homeownership in markets with high average home prices, US policymakers must address this affordable housing shortage.

Housing is especially expensive in the District of Columbia, where the price for a two-bedroom home reached approximately $\$ 477,000$ by March of this year (Zillow 2015). In the same year, the District of Columbia's Area Median Income (AMI) was calculated by the Department of Housing and Urban Development to be approximately $\$ 107,000$ per household (HUD 2014). A household is considered very low income if its income is under 50 percent of the AMI (e.g., \$53,500) for a four-person household), and a household is considered low income if its income is under 80 percent of the AMI (e.g., $\$ 68,500$ for a four-person household) (HUD 2014). Both sets of households are far below the income threshold required to qualify for a mortgage to purchase a two-bedroom DC home, even though these households may be made up of workers that communities depend on, such as preschool 
teachers and security guards, who on average earned $\$ 22,575$ and $\$ 37,625$ in the District of Columbia in 2012, respectively (CHSTF 2013). The result of this disparity between average home price and average income for a low- or moderate-income homebuyer is that low- and moderate-income residents continue to be priced out of the market despite the fact that the DC housing market is growing and the DC government issued permits to construct 4,162 new housing units in 2012 (DHCD 2013).

One strategy the DC government has employed to address housing affordability and to increase the number of available affordable units is the Inclusionary Zoning (IZ) affordable housing program, established by the Inclusionary Zoning Implementation Amendment Act of 2006. The Department of Housing and Community Development (DHCD) administers the DC IZ program, and the program's final implementation guidelines were published in the DC Register in December 2009. This IZ program mandates that all new housing developments set aside units for low- and moderate-income purchasers at below-market prices. These units remain permanently restricted for sale to low- and moderate-income residents in order to maintain affordability. ${ }^{1}$

In the following paper, I discuss the District of Columbia's IZ program and explore the costs of producing affordable housing through IZ with the current resale restrictions. I then compare the District of Columbia's IZ program with the IZ program in San José, California. Based on this comparison, I provide recommendations as to how the DC IZ program can be revised to provide the most economic value to target populations and to the DC community as a whole.

\section{The District of Columbia Inclusionary Zoning Affordable Housing Program}

Though US IZ programs vary widely in terms of implementation, they typically include four common elements: mandates for developers to produce a certain percentage of units priced at below-market prices, incentives for builders to provide these units, income restrictions on IZ unit buyers, and resale restrictions on IZ unit owners (Bento, Knapp, and Lowe $2008,4)$. In the District of Columbia, the program is mandatory for many developers. To be issued a permit for a new building development with 10 or more units, or to increase the size of an existing building by over 50 percent, a builder must set aside 8 to 10 percent of units to be sold to qualifying low- and moderate-income buyers. Each year, maximum prices are set for IZ units based on whether they are designated for sale to low-income households (earning 50 percent of the District of Columbia's AMI) or moderate-income households (earning 80 percent of the District of Columbia's AMI). For each income category, the price is set so that a family earning the maximum income for that income category would spend no more than 30 percent of its monthly income on housing. Maximum prices also depend on the size of each unit. For example, based on the District of Columbia's 2012 AMI, the maximum price for a one-bedroom condominium sold to a low-income household would be $\$ 141,300$, while a threebedroom unit sold to a moderate-income household could reach $\$ 329,300$ (DHCD 2013). To defray the cost of selling units below market prices, developers receive density bonus incentives that allow them to build to a 20 percent higher floor area ratio than would otherwise be allowed under

1. $\quad$ DC Code 6-1041.07. 
DC zoning regulations. ${ }^{2}$

Qualifying households must participate in homeownership counseling through an approved community-based group prior to registering for a lottery to participate in the program. ${ }^{3}$ Families must be chosen through the lottery process before having the chance to move forward with purchasing a unit. The District of Columbia's IZ units are permanently restricted, meaning that IZ owners can only sell their units to buyers in the same income category. Resale prices are determined through a formula defined by DHCD. The maximum resale price formula sums the price originally paid by the owner, the value of any eligible capital improvements made by the owner during their tenure, and a factor to account for inflation. ${ }^{4}$ In this way, IZ units are permanently reserved for the lowand moderate-income market beyond the tenure of the original purchaser.

\section{Economic Costs Associated with Resale Restrictions on IZ Units}

IZ proponents often argue that because IZ relies on the private market to increase the stock of affordable housing, instead of provisioning public housing or providing subsidies to residents, programs can be implemented at little or no cost to governments (Dietderich 1996, 44). Government funds that would have paid for affordable housing can be redirected to provide other services. However, despite the fact that IZ programs are not publicly funded (aside from the minimal costs of passing legislation and administering the program), there are opportunity costs associated with them. In the case of the DC IZ program, the resale restriction placed on current IZ unit owners imposes economic costs. These costs

\footnotetext{
2. DC Municipal Regulation 11-2604.

3. DC Municipal Regulation 14-2209.

4. DC Municipal Regulation 14-2218.
}

have proven detrimental to the program's success, and as of December 2013, only three IZ units have been sold in the District of Columbia, with an additional four either sold or in the selection process (out of the nine produced for sale as of December 31, 2013) (DCHD 2014).

At the most basic level, there is an opportunity cost associated with a housing unit being sold below market value (Powell and Stringam 2005). This opportunity cost is the difference between the restricted sales price and the price at market value, and it represents revenue that could have been earned by developers and instead contributed to the total economic surplus gained by consumers of IZ units. IZ policies thus create deadweight loss by moving away from the Pareto efficient outcome, or the allocation of resources in which one person or group cannot be made better off without making another worse off.

In addition to creating a permanent surplus loss in the housing market, restricting sale prices may also negatively affect IZ unit owners. Owners do receive the benefit of maintaining a home at below-market rates. However, permanent resale restrictions keep targeted populations from advancing economically by taking away "the only substantial asset many lower income families have, making the units more akin to rental or limited equity cooperatives" (Scruggs 2013, 3).

It is noteworthy that the resale restrictions as defined in the IZ Unit Owner Covenant potentially create an additional opportunity cost in terms of the capital originally spent by the household on the unit itself. Going back to the one-bedroom low-income example, if a household were to commit to purchasing a $\$ 141,300$ one-bedroom IZ unit under the restrictions described above, the household could 
gain only a small margin above the original payment price. The household thus faces the opportunity cost of capital in that the cost of the property may gain a better return elsewhere, perhaps invested in an IRA as stock market returns could be much higher. While there is a small return on investment from the sale of an IZ unit, it is much less than the return from the sale of the unit at market value. There are also significant transaction costs involved with selling any home, and selling an IZ unit may be particularly difficult. If the transaction costs are high enough, a seller could face a 0-percent return or even a loss. Additionally, one of the barriers facing low-income buyers is the ability to qualify for an affordable mortgage. In general, the Federal Housing Administration (FHA) insures mortgages to households that can demonstrate good credit and will finance the housing price up to 96.5 percent with a 3.5 percent down payment, making these loans attractive to low- and moderate-income households (HUD 2015). However, because of IZ resale restrictions, the FHA has thus far been unwilling to grant loans to households seeking to purchase IZ properties in the District of Columbia (Scruggs 2013). The reasoning behind this refusal to insure loans for IZ properties is that if the purchaser is unable to repay their loan and the FHA forecloses on the property, the FHA will be unable to resell the property for anything more than the maximum price stated in the IZ covenant and will likely face a loss on the transaction.

While proponents may hail the DC IZ program as an income redistribution program that relies on private developers to produce affordable units at little direct cost to the local government and taxpayers, there are economic costs paid by
IZ unit developers, IZ unit owners, and the community at large. When evaluating the effectiveness of IZ as an income redistribution program, it is important to recognize these economic costs and to evaluate them against the value of the economic good provided by offering affordable housing to low- and moderate-income DC residents. Because the DC IZ program is relatively new, there is not yet a large empirical dataset to evaluate how well the program is serving low- and moderate-income residents. To appraise the DC IZ program in the absence of such data, I compare it to another urban IZ program in San José, California, in the next section.

\section{The San José Inclusionary Zoning Model}

San José, California, implemented an IZ policy as part of a statewide initiative known as the Regional Housing Needs Assessment (RHNA). Under RHNA, San José was required to produce approximately 19,000 new for-sale and rental housing units prior to 2014. Despite legal challenges, approximately 200 IZ ownership units have been produced in San José to date (Scruggs 2013, 9). Unlike the DC IZ program's 10 percent requirement, San José's IZ program requires at least 15 percent of for-sale units in new developments with over 10 units to be designated as affordable for low- and moderate-income residents. San José's program also requires at least 6 percent of these affordable for-sale units to be available to very low-income households and 9 percent to be available to low- and moderate-income households). ${ }^{5}$ Income thresholds are based on Santa Clara County's 2014 AMI of \$101,900 (HUD 2014). For example, in 2014, very low income was defined as a four-person household earning up to $\$ 50,950$ per

5. San José Municipal Code 5.08. 
year (or 50 percent of the AMI), low income was defined as a four-person household earning up to $\$ 71,300$ per year (or under 80 percent of the AMI) (HUD 2014), and moderate income was defined as a four person household earning up to $\$ 114,128$ (or under 120 percent of the $\mathrm{AMI}^{6}$ ) (moderate income definition based on author's calculation) (HUD 2014). Developers are required to calculate the maximum amount a prospective qualifying buyer is able to spend and, when approved by the city of San José, to lower the price from the market price to the homebuyers' affordable price. Furthermore, unlike in the DC IZ program, San José developers may pay a fee or agree to construct affordable units outside the proposed development to avoid the IZ restriction.

The feature of San José's IZ program that is the most divergent from DC's is the shared equity resale provision. San José allows IZ unit owners to resell their units at market prices and earn a portion of the unit appreciation. The IZ program recaptures the amount of the "developer discount loan," or the difference between the market price and the amount paid by the owner, and allows the owner to retain any appreciation on the original market value price. For example, based on a 30-percent spending limit on annual income, a moderate-income homebuyer making $\$ 84,000$ per year would be able to afford about $\$ 2,450$ in housing costs per month. If one estimates that property taxes and homeowner fees cost $\$ 300$ per month, the affordable monthly payment drops to $\$ 2,150$. Further assuming the homebuyer has a 30-year fixed-rate mortgage and pays a conservative 5 percent interest rate, the maximum allowable price for a three-bedroom unit would be approximately $\$ 400,000$. If the mar-

\footnotetext{
6. California Health and Safety Code 50093.
}

ket rate for the three-bedroom San José condominium in question were $\$ 550,000$, the developer discount loan would be $\$ 150,000$. If the homebuyer decided to sell the unit, they would be responsible for repaying the San José government this $\$ 150,000$ developer discount loan, but they would be able to retain the rest of the proceeds. San José reinvests revenue from repaid developer discount loans into affordable housing projects to account for the lost affordable housing unit.

This so-called subsidy recapture provision maintains the affordability of housing while allowing the market to determine prices and addresses many of the economic costs associated with resale restriction of the DC IZ program. As expressed by author Laura Padilla $(1995,557)$ :

There are two major benefits to the recapture approach. First, it responds to the objection that resale controls overly regulate the free market by allowing an owner to sell a unit to any willing buyer, at a price determined by the market. Second, it prevents a seller from obtaining a windfall profit.

While the builder is still responsible for subsidizing the original purchase through the developer discount loan, the deadweight loss resulting from the price ceiling set to make the units affordable can later be recovered through sale to willing buyers on the open market. Therefore, the part of the surplus lost through the sale of an IZ unit is recovered and contributes to the social good, or total amount of consumer surplus. The recapture provision also addresses the opportunity cost of capital associated with making a 0 -percent or minimal return on the investment of purchasing an IZ unit. Property rights are reestablished by allowing low- and moderate-income 
homebuyers more freedom over their property, not constraining their ability to resell. IZ homebuyers maintain an appreciable asset and, if they choose to sell, may see a return on their investment. In this way, many of the longer-term social and economic benefits of homeownership cited above, such as wealth accumulation and housing security (McCarthy, Rohe, and Van Zandt 2001), will accrue to IZ homebuyers.

Finally, because the San José IZ buyer does not sign a covenant restricting the resale of units to households with comparable income levels, they have greater access to affordable mortgages from lenders and insurers (namely, the FHA). When units are open to sale on the regular housing market, lenders and insurers recognize that they would lose less in the case of foreclosure. In fact, in the case of foreclosure, a lender or insurer would only be responsible for the amount of the developer discount loan promised to the San José government at the time of the original sale. Improved access to financing options increases affordability for low- and moderate-income families who might not otherwise qualify for a loan.

\section{Conclusion}

The intention of the District of Columbia's IZ affordable housing program is to provide low- and moderate-income residents with the means to purchase housing in a market where prices are continually on the rise and the goal of homeownership can seem out of reach. The DC IZ program has attempted to achieve this goal by mandating that developers set aside a percentage of certain newly developed and redeveloped units for purchase below market prices to qualifying low- and moderate-income homebuyers. These units are permanently restricted for resale to buyers within the same income category and resale prices are capped.

While the purpose of these restrictions is to prevent windfall profits for low- and moderate-income buyers and to maintain the current supply of affordable properties, there are other models available that could inform a revision of the DC provision to recapture some of the economic losses resulting from resale restrictions. The San José recapture model allows the purchasers of IZ units to resell their properties at market value after repaying the subsidy, retaining the rest of the value of the appreciation on the property during their tenure. This allows the appreciated value of the unit back into the market, increasing the total surplus and decreasing the deadweight loss caused by the IZ regulation. The recapture also addresses the opportunity cost of capital for the IZ buyer by allowing them to maintain an appreciable asset and realize a gain if they choose to sell the unit back into the housing market. Finally, recapture as opposed to restriction allows lowand moderate-income buyers to more easily obtain an affordable mortgage.

Of course, even with its merits, the San José recapture model for the resale of IZ properties is not without risk. Depending on the economic climate and housing market at the time of sale, the recapture subsidy may not cover the costs of financing an equal number of affordable units (Padilla 1995, 557). It is beyond the scope of this paper to analyze the circumstances in which a recapture model may actually lead to a reduction in the number of units (if the recapture subsidies do not compensate for the loss of units), and the empirical data are not available to form a conclusion either way.

In this paper, I have attempted to clarify the economic costs associated with the DC IZ program. Accord- 
ingly, I would recommend that the DC IZ program, specifically the resale restriction provision, be amended to allow the resale of IZ units at market prices, with the difference between the original market price and the original purchase price (i.e., the subsidy) recaptured by the DC government for use in maintaining affordable housing for low- and moderate-income residents. In this way, the DC IZ program would more effectively function as an income redistribution program while reducing the economic costs of resale restrictions and providing current and future low- and moderate-income DC households with a means for longterm housing security.

\section{References}

Bento, Antonio, Gerrit-Jan Knapp, and Scott Lowe. 2008. “Housing Market Impacts of Inclusionary Zoning." National Association of Home Builders. Accessed April 19, 2014. http:/ / www.nahb.org/fileUpload_details. aspx? contentID $=220527$.

CHSTF (Comprehensive Housing Strategy Task Force). 2013. "Bridges to Opportunity: A New Housing Strategy for DC." Accessed April 22, 2014. http:/ / taskforce2012.org/Portals / 1 / docs / Bridges_to_OpportunityA_New_Housing_Strategy_for_DC-Official_Report.pdf.

Cort, Cheryl. 2013. "Inclusionary Zoning Making Slow Progress." Greater Greater Washington, September 24. Accessed April 19, 2014. http:/ / greatergreaterwashington.org / post/20150/inclusionary-zoning-making-slow-progress /.

DHCD (District of Columbia Department of Housing and Community Development). 2013. "Inclusionary Zoning Annual and 5.5 Year Report." Accessed April 20, 2014. http:/ / dhcd.dc.gov/ publication/2012-inclusionary-zoning-annual-report.

2014. "Inclusionary Zoning 2013 Annual Report." Accessed March 15, 2015. http: / / dhcd.dc.gov/ sites / default / files / dc/ sites / dhcd/ publication/ attachments / 2013\%20Inclusionary\%20Zoning\%20Annual\%20 Report.pdf.

Dietderich, Andrew G. 1996. “An Egalitarian's Market: The Economics of Inclusionary Zoning Reclaimed." Fordham Urban Law Journal 24(1):23-104.

HUD (Department of Housing and Urban Development). 2014. FY 2014 Income Limits Documentation System. Accessed March 15, 2015. http:/ / www.huduser.org/portal/datasets/il/il14/index_il2014.html.

2015. "How Can FHA Help Me Find a Loan?" Accessed March 28, 2015. http: / / portalapps.hud.gov/FHAFAQ/ controllerServlet?method =showPopup\&faqId=1-6KT-1457.

McCarthy, George, William Rohe, and Shannon Van Zandt. 2001. “The Economic Benefits and Costs of Homeownership: A Critical Assessment of the Research." Working Paper No. 01-02. Accessed May 1, 2014. http:/ / www.housingamerica.org/RIHA/RIHA/Publications / 48517_RIHAwp01-02.pdf.

Neibauer, Michael. 2013. "Average DC Home Sold for More than 800K in September." Washington Business Journal, November 5. Accessed May 1, 2014. http:/ / www.bizjournals.com/washington/breaking_ ground/2013/11/ average-dc-home-sold-for-more-than.html. 
Padilla, Laura. 1995. "Reflections on Inclusionary Housing and a Renewed Look at its Vitality." Hofstra Law Review 23(3):539-626.

Powell, Benjamin, and Edward Stringham. 2005. "The Economics of Inclusionary Zoning Reclaimed: How Effective Are Price Controls?" Florida State University Law Review 33(2):471-500.

Scruggs, Sarah. 2013. "Inclusionary Zoning Ownership: Lessons for the District from Comparable Cities." Accessed April 20, 2014.. http:/ / hatdc. org/wordpress / wp-content/uploads/IZ-Ownership-Lessons-for-theDistrict-.pdf.

Sturtevant, Lisa. 2013. “Demand for Condos in Washington DC-Area Market Intensifies." The Washington Post, January 23. Accessed May 1, 2014. http:/ / www.washingtonpost.com/blogs/where-we-live/post/demand-for-condos-in-washington-dc-area-market-intensifies / 2013/01/2 2/0ad908f8-64b4-11e2-b84d-21c7b65985ee_blog.html.

Sturtevant, Lisa, and Janet Viveiros. 2014. "The Housing Affordability Challenges of America's Working Households." Center for Housing Policy. Accessed April 28, 2014. http:/ / www.nhc.org/media/ files/Landscape2014.pdf.

Zillow. 2015. "Washington Home Prices and Values." Accessed March 15, 2015. http:/ / www.zillow.com/washington-dc/home-values/.

Laura Gibbons is a second-year Master of Public Policy student at the George Washington University, focusing on social policy in education and urban issues. She earned her Bachelor of Arts in International Relations and English from Bucknell University and completed a year of AmeriCorps service in Philadelphia before relocating to the District of Columbia. Laura has been living in DC for the greater part of seven years, working as a defense contractor for the US Navy. Laura continues to work full time while pursuing her MPP and attempts to take advantage of the many extracurricular learning activities that GW and the Trachtenberg School have to offer. This is her first scholarly publication, and she is honored to have been given the opportunity to contribute to Policy Perspectives. After graduation, Laura plans to embark on a career in public service by pursuing federal service opportunities.

The author would like to thank the Policy Perspectives editorial team, particularly her Associate Editor Megan Wolfe, for their dedication to this project, their fresh eyes, and their extremely helpful insights into the article throughout the review phase. She would also like to thank her faculty reviewer, Professor Leah Brooks, for taking the time out of her schedule to offer input and suggest areas of improvement, both of which have had an influence on the final product. She would like to offer special thanks to Professor Gerald Brock, who taught her the importance of considering the economic costs of all policy choices, even the most well-meaning. Finally, she would like to thank her parents and her partner Greg for their continued support of all her pursuits, academic and otherwise. 